Review Article

\title{
Clocking In Time to Gate Memory Processes: The Circadian Clock Is Part of the Ins and Outs of Memory
}

\author{
Oliver Rawashdeh (D), ${ }^{1}$ Rex Parsons, ${ }^{1}$ and Erik Maronde ${ }^{2}$ \\ ${ }^{1}$ School of Biomedical Sciences, The University of Queensland, Brisbane, QLD, Australia \\ ${ }^{2}$ Department of Anatomy, Goethe University Frankfurt, Frankfurt, Germany \\ Correspondence should be addressed to Oliver Rawashdeh; o.rawashdeh@uq.edu.au
}

Received 3 October 2017; Revised 22 January 2018; Accepted 5 February 2018; Published 12 April 2018

Academic Editor: Oliver Stork

Copyright (C) 2018 Oliver Rawashdeh et al. This is an open access article distributed under the Creative Commons Attribution License, which permits unrestricted use, distribution, and reproduction in any medium, provided the original work is properly cited.

\begin{abstract}
Learning, memory consolidation, and retrieval are processes known to be modulated by the circadian (circa: about; dies: day) system. The circadian regulation of memory performance is evolutionarily conserved, independent of the type and complexity of the learning paradigm tested, and not specific to crepuscular, nocturnal, or diurnal organisms. In mammals, long-term memory (LTM) formation is tightly coupled to de novo gene expression of plasticity-related proteins and posttranslational modifications and relies on intact cAMP/protein kinase A (PKA)/protein kinase C (PKC)/mitogen-activated protein kinase $(\mathrm{MAPK}) / \mathrm{cyclic}$ adenosine monophosphate response element-binding protein (CREB) signaling. These memory-essential signaling components cycle rhythmically in the hippocampus across the day and night and are clearly molded by an intricate interplay between the circadian system and memory. Important components of the circadian timing mechanism and its plasticity are members of the Period clock gene family (Per1, Per2). Interestingly, Per1 is rhythmically expressed in mouse hippocampus. Observations suggest important and largely unexplored roles of the clock gene protein PER1 in synaptic plasticity and in the daytime-dependent modulation of learning and memory. Here, we review the latest findings on the role of the clock gene Period 1 (Perl) as a candidate molecular and mechanistic blueprint for gating the daytime dependency of memory processing.
\end{abstract}

\section{Memory Systems}

1.1. Definition. Memory can be defined as "the retention of experience-dependent internal representations or of the capacity to reactivate or reconstruct such representations over time" [1]. "Internal representations" in the definition of memory refers to neuronal encoded representations of the surrounding environment that could guide behavior. This definition of memory fits well with the many levels of neuroscientific research [1-4] and originates from the view that all memories regardless of species and task are biological internal representations [4]. We have to bear in mind, however, that "internal representations" could also be innate constructs encoded by genes and established by developmental programs not necessarily related to learning [4].

1.2. History. "Memory" was initially viewed as a simple, unitary faculty of the mind and brain [5]. Later, converging evidence emerged from different scientific fields that suggested the existence of multiple dissociable memory systems [6-8]. This, however, does not mean that different memory systems can be separated according to conventional distinctions between stimulus modalities (visual or auditory) and response modalities (manual or verbal), but rather refers to different neural substrates. Evidence for the existence of multiple memory systems emerged from observations showing that different forms of brain damage in humans or experimentally imposed lesions to specific brain areas can severely impair specific forms of memory without affecting others $[5,9]$. For example, lesions to the caudate nucleus or to the temporal stem connecting the inferior temporal cortex to other brain structures, among which is the caudate nucleus, impairs acquisition in monkeys trained for a long-term visual discrimination task [10-12] without influencing the acquisition of other learning tasks, like the delayed nonmatch to sample task (DNMS) [12]. Lesions to the 
hippocampus/amygdala disrupt acquisition for DNMS but not acquisition for the long-term visual discrimination task [12-14]. The information gathered from lesion experiments was consolidated into a representative map to visualize the idea of multiple memory systems and to illustrate the neural substrates involved in memory processing and storage.

1.3. Short-Term and Long-Term Memory. Memories can also be defined in terms of the time elapsed since information encoding. Accordingly, memories are divided into shortterm and long-term memories. In general, the memory that persists for only a short period and is directly accessible after the learning experience took place is known as short-term memory (STM). Short-term memory is a labile form of memory in the context of time and is sensitive to disruption through disturbances like electroconvulsive shocks [15]. Memories that appear at a later stage after learning and last for a long time are known as long-term memories (LTM). Long-term memories are more stable forms of memories.

Psychologists have come to distinguish between STM and LTM in reference to consciousness (declarative), without focusing too much on the time lapse between information encoding and retrieval. Psychologist William James (1890) argued that primary memory or short-term memory can exist indefinitely as long as one's attention remains focused on a specific given piece of information (continuous rehearsal). However, once the information leaves consciousness (rehearsal is interrupted), even if retrieval occurs seconds later, the retrieval of that information will now involve a secondary memory system or long-term memory system.

\section{The Circadian System and Learning and Memory}

In 1885, Ebbinghaus discovered the exponential nature of forgetting, also known today as the retention curve or forgetting curve, depending on how the data is presented. In general, the retention curve presents a decline over time in the retention of what was learned [16]. In 1957, Kamin presented a retention curve for avoidance learning using rats [17]. However, the retention curve Kamin plotted was somewhat different from Ebbinghaus's retention curve. Kamin's retention curve was " $U$ "-shaped with a minimum retention score at one hour after training. At $6 \mathrm{~h}$ and $24 \mathrm{~h}$ posttraining, the animal's memory performance was similar to the original performance measured at $1 \mathrm{~min}$ posttraining. Kamin postulated that one possibility to explain the " $U$ "-shaped curvilinear function was to assume the existence of two memory systems: one memory system that dominates retention immediately after training and loses strength over time (short-term memory or primary memory system) and a secondary memory system that starts to dominate at some later stage following training, probably after some time of consolidation, and increases in strength over time. This secondary memory system is represented in Kamin's retention curve as the second rise in the "U"-shaped curve. In fact, the secondary rise in this " $U$ "-shaped curvilinear function is considered to be a behavioral indicator for memory consolidation [18].

Holloway and Wansley [19] revisited the original study by Kamin using a passive avoidance training protocol with, however, a testing interval of $6 \mathrm{~h}$ for $72 \mathrm{~h}$ posttraining. Unexpectedly, the observed retention deficit in passive avoidance behavior appeared to be alternating, suggesting the involvement of some rhythmic biological factor(s) in the fluctuation of retention [19]. Soon thereafter, the group reported in a new study that the rhythmicity (6h period) in retention performance reflected the inability to retrieve the newly learned experience as a result of some rhythmic internal state (state-dependent hypothesis) [20-22]. In 1975, Holloway provided additional supporting evidence consistent with the biological rhythm hypothesis, by showing that the repeated retention deficits in active and passive avoidance tasks were absent in rats whose "master circadian clock," residing within the suprachiasmatic nucleus of the hypothalamus, was lesioned [22, 23].

2.1. Indirect Evidence. In recent years, the interest in the importance of the circadian system in health expanded explosively as evident by daily supporting scientific research and media coverage, linking health-related issues (physiological, psychological, and behavioral) to circadian disturbances. Thus, the saying "a healthy mind in a healthy body" has much truth to it. In regard to the importance of the integrity of the circadian system, the proverb could be further elaborated to "a healthy mind in a body with an intact circadian system.”

Many processes that influence memory, such as protein and neurotransmitter synthesis, synaptic activity, excitability, and hormone secretion, exhibit circadian oscillations $[24,25]$. Thus, memory processes could be circadianregulated through the rhythmic action of biochemical processes that influence memory formation. Holloway, after his initial work with Wansley, pursued the idea of the involvement of the circadian system in learning and memory. Holloway assumed that if an organized circadian system plays a modulation role in learning and memory, then a disruption of the organism's circadian system should affect memory processing. Accordingly, Tapp and Holloway addressed the importance of the circadian organization for normal memory processing by disrupting the circadian system of rats via phase shifting their light-dark cycle immediately after training. Rats that were trained on a one-trial passive avoidance task followed by a shift in their original light-dark cycle showed retention deficits [26]. Furthermore, the same retention deficit was also observed when rats were subjected to the same phase shift, but several days after training. The interpretation was that the amnesic effects of the phase shift were dependent on the time interval between the training and the phase shift. Tapp and Holloway also showed that the amnesic effect of circadian disorganization was not due to training and testing the animals in different circadian phases. Interestingly, the results could be divided into two clusters categorized as normal and poor retention scores. Astonishingly, the group of rats 
that showed poor retention performance also demonstrated abnormal reentrainment to the shifted light-dark cycles. In summary, circadian disorganization affects memory processing and supports the idea for the involvement of a circadian component in the modulation of learning and memory.

It was later demonstrated that phase shifts immediately after training or shortly before training result in retention deficits without, however, affecting more innate behaviors such as social interaction and exploration [27]. Since retention performances appear normal when testing takes place after reentrainment, the amnesic effect of circadian disorganization is more specific for memory retrieval. Fekete et al. [27] later found that the effect of the phase shift on memory retrieval during testing can be attenuated by treatment with pituitary hormones, ACTH, and vasopressin [28]. ACTH has been proposed to improve motivation and attention and increase arousal [29]. Additional evidence for the importance of an intact circadian organization in normal memory processing came from studies using a conditioned place preference task to investigate the relationship between rhythm integrity and the ability to form cognitive associations [30]. Accordingly, a consolidated circadian rhythm is a prerequisite to develop a preference for a specific context associated with a rewarding stimulus.

At the time, it was unclear whether all memory systems are influenced by the circadian system similarly. Although circadian disruption in rats also influences hippocampus-specific memory processes, the results by Devan et al. [31] suggested a consolidation view rather than a temporary memory retrieval explanation [27]. This was because animals reentrained to the new light-dark cycle for 17 days still showed retention deficits. Furthermore, a series of experiments showed that training and testing for a place navigation task in different circadian phases have no effect on the expression of this learning task. In conclusion, the different neuroanatomical substrates known to be involved in memory processing can be differentially modulated by the circadian system.

2.2. Direct Evidence. Using a more direct approach to show the involvement of the circadian system, Colwell's lab demonstrated that mice trained for tone, and contextual fear conditioning, learned the tasks faster during the night as compared to daytime and that memory retrieval for the acquired task was better during the day than during the night. This diurnal rhythm in acquisition and retention persisted in constant conditions (darkness). Furthermore, when animals were entrained to a reversed light-dark cycle, the rhythm in acquisition and retention also reversed [32]. Collectively, these results suggest that both acquisition and memory retrieval are circadian-modulated and provide the first direct evidence for a circadian modulation of memory processing in mammals.

Diurnal phase-dependent differences in the efficiency of memory acquisition and retention were shown in the melatonin-proficient $\mathrm{C} 3 \mathrm{H}$ mouse strain and the melatonindeficient C57 strain [32]. At first glance, these results were indicative that melatonin plays no significant role. However, a closer look at the profile of the acquisition curves for both strains reveals that in $\mathrm{C} 3 \mathrm{H}$ mice, the degree of freezing was much more robust following the last training stimulus in mice trained during the day only. In C57 mice, however, significant day and night differences in the magnitude of freezing were only observed after their initial training stimulus. This suggested that elevated melatonin levels during the night might have a suppressive effect on learning the fear-conditioning paradigm and therefore may have a functional role in the rhythmic modulation of acquisition by the circadian system.

To determine whether the circadian modulation of different memory processes (acquisition, consolidation, and retrieval) is dependent on the neuronal substrate involved, mice were tested twice for two different cuedependent fear conditioning paradigms, hippocampusdependent (context-dependent fear conditioning) and hippocampus-independent (tone-cued conditioning). It was noted that the hippocampus-dependent conditioning and rate of extinction were more pronounced in their phase dependency as compared to the hippocampusindependent tone-cued conditioning [33]. This study along with previous findings supports the idea that different memory processes, dependent on the neuronal substrate(s) involved, are selectively regulated by the circadian system.

Importantly, choosing the right experimental parameters and conditions is essential to differentiate between phase-dependent differences in memory processes as opposed to phase-dependent differences in animal performance. A classic example is the study by Valentinuzzi et al. [34], showing that what appears at first glance as a phase-dependent difference in acquisition and retention is actually phase-dependent differences in performance, like search pattern and swimming speed as a result of daytimedependent differences in the animal's motivation to escape from the water maze.

Is the circadian modulation of memory processing evolutionary conserved? Fernandez et al., using Aplysia californica, a diurnal invertebrate, showed for the first time that longterm sensitization for tail/siphon withdrawal reflex conditioning is more robust for daytime training when tested $24 \mathrm{~h}$ later, as compared to long-term sensitization for nighttime training [35]. Interestingly, short-term sensitization did not differ in a phase-dependent manner, which again appears to be evolutionarily conserved since studies using rodents show similar results $[32,36]$. Drosophila melanogaster on the other hand does show a circadian modulation of short-term memory [37] and was the first model to show the involvement of the clock gene Period (Per) in long-term memory [38].

2.3. Where Is the Clock? In mammals, most rhythms in physiology and behavior are downstream outputs of the circadian clock of the SCN; it would, therefore, be reasonable to speculate that the clock of the SCN is modulating memory processes. In fact, Ralph's lab investigated whether the rhythm in context learning persisted in the absence of a functional SCN clock [39] similar to the approach Holloway used when he showed that in the absence of the SCN the Kamin effect 
TABLE 1: Circadian modulation of memory-relevant signaling in rodents.

\begin{tabular}{|c|c|c|c|c|c|c|c|c|}
\hline $\begin{array}{l}\text { Signaling } \\
\text { molecule }\end{array}$ & $\begin{array}{l}\text { Short-term } \\
\text { memory }\end{array}$ & Model organism & $\begin{array}{l}\text { Long-term } \\
\text { memory }\end{array}$ & Model organism & $\begin{array}{l}\text { Memory } \\
\text { retrieval }\end{array}$ & $\begin{array}{c}\text { Model } \\
\text { organism }\end{array}$ & $\begin{array}{l}\text { Circadian/diurnal } \\
\text { rhythmicity }\end{array}$ & $\begin{array}{l}\text { Model } \\
\text { organism }\end{array}$ \\
\hline cAMP & $\checkmark$ & Wistar rats [104] & $\checkmark$ & $\begin{array}{l}\mathrm{C} 57 \mathrm{BL} / 6 \times 129 / \\
\text { Ola mice }[105]\end{array}$ & - & & $\checkmark$ & $\begin{array}{c}\text { C57/BL6 mice } \\
\text { [69] }\end{array}$ \\
\hline PKA & $\mathrm{X}$ & $\begin{array}{c}\text { C57BL/6J mice } \\
{[47,106]} \\
\text { Sprague-Dawley } \\
\text { rats }[107]\end{array}$ & $\checkmark$ & $\begin{array}{c}\text { C57BL/6J mice } \\
{[106,108]} \\
\text { Sprague-Dawley } \\
\text { rats }[107]\end{array}$ & - & & $\checkmark$ & $\begin{array}{l}\mathrm{C} 3 \mathrm{H} / \mathrm{H} 3 \mathrm{~N} \\
\text { mice }[64]\end{array}$ \\
\hline PKC & $\checkmark$ & $\begin{array}{c}\text { Wistar rats [109, } \\
110]\end{array}$ & $\checkmark$ & Wistar rats [111] & $\checkmark$ & $\begin{array}{l}\text { CD1 mice } \\
{[112]}\end{array}$ & $\checkmark$ & $\begin{array}{l}\mathrm{C} 3 \mathrm{H} / \mathrm{HeN}[64] \\
\text { mice }\end{array}$ \\
\hline pMAPK & - & & $\checkmark$ & C57/BL6 [113] & $\checkmark$ & $\begin{array}{l}\text { C57BL/6 } \\
{[114,115]}\end{array}$ & $\checkmark$ & $\begin{array}{c}\text { C57/BL6 mice } \\
{[69,116]}\end{array}$ \\
\hline pCREB & $\mathrm{X}$ & $\begin{array}{l}\text { Wistar rats [117] } \\
\text { Long-Evans } \\
\text { hooded rats [118] }\end{array}$ & $\checkmark$ & $\begin{array}{l}\text { Wistar rats [117] } \\
\text { Long-Evans } \\
\text { hooded rats [118] }\end{array}$ & $\mathrm{X}$ & $\begin{array}{l}\text { C57BL/6 } \\
\text { mice }[119]\end{array}$ & $\checkmark$ & $\begin{array}{c}\mathrm{C} 3 \mathrm{H} / \mathrm{H} 3 \mathrm{~N} \\
\text { mice }[64] \\
\text { C57/BL6 mice } \\
{[69]}\end{array}$ \\
\hline $\mathrm{AC}$ & $\checkmark$ & $\begin{array}{l}\mathrm{C} 57 \mathrm{BL} / 6 \times 129 / \\
\mathrm{SV} \text { mice }[120]\end{array}$ & $\checkmark$ & $\begin{array}{l}\mathrm{C} 57 \mathrm{BL} / 6 \times 129 / \\
\mathrm{SV} \text { mice }[120]\end{array}$ & - & & - & \\
\hline CAMKIV & $\mathrm{X}$ & $\begin{array}{c}\text { C57BL/6N mice } \\
{[121]}\end{array}$ & $\checkmark$ & $\begin{array}{c}\text { C57BL/6 mice } \\
{[122]}\end{array}$ & - & & $\checkmark$ & $\begin{array}{c}\text { WKY rats } \\
{[123]}\end{array}$ \\
\hline CAMKII & $\mathrm{X}$ & $\begin{array}{c}\text { 129/BL6 mice } \\
{[124]}\end{array}$ & $\checkmark$ & $\begin{array}{c}\text { 129/BL6 mice } \\
{[124]}\end{array}$ & $\mathrm{X}$ & $\begin{array}{c}\text { Wistar rats } \\
\text { [125] }\end{array}$ & $\checkmark$ & $\begin{array}{c}\text { C57BL/6 mice } \\
{[116,126]}\end{array}$ \\
\hline
\end{tabular}

$\checkmark$ : effect; X: no effect; - : unknown; cAMP: cyclic-adenosine monophosphate; PKA: protein kinase A; PKC: protein kinase C; pMAPK: phosphorylated mitogen-activated protein kinase; pCREB: phosphorylated cAMP response element-binding protein; AC: adenylyl cyclase; CAMKIV: calcium/calmodulindependent protein kinase type IV; CAMKII: calcium/calmodulin-dependent protein kinase type II.

disappeared [23]. The main finding of this study is that the phase-dependent effect on learning the conditioned place preference task continued in animals lacking a functional SCN clock, suggesting the existence of an oscillator other than and independent of the SCN clock that is influencing learning. Differences in SCN dependency likely depends on the learning paradigm used. The latter is known to define the neuronal substrates involved which in turn could be influenced by distinct circadian networks. Spatial memory for instance which involves the dorsal hippocampus is again SCN-dependent [40].

This raises the intriguing question of whether the hippocampus houses a circadian oscillator and if it does, what is its function? Several studies have shown that clock gene reporter mice show rhythmic luciferase activity for the Per2 gene in the hippocampus [41], in addition to recent findings showing that all major clockwork components of the transcriptional/translational feedback loop (TTFL) are rhythmically expressed in the hippocampus [42]. The question of what the function of the hippocampal oscillator exactly is and how it regulates hippocampal function, if at all, remains a very hot topic. We will focus on the hypothesis that suggests that clockwork components impose a modulatory function on the molecular signature involved in memory formation, thereby imposing a circadian modulation on memory processing. To short list molecular candidates targeted by cycling clockwork components requires knowledge about the key signaling and structural molecules that define the different forms of memory (short and long term) as well as the different memory processes (see Table 1).

\section{PERIOD1 as a Modulator of Hippocampal Function}

In the mouse hippocampus, long-term memory (LTM) formation is tightly coupled to de novo gene expression of plasticity-related proteins and posttranslational modifications [43-45] and relies on intact cAMP/protein kinase A (PKA)/protein kinase C (PKC)/CREB/ERK signaling [43, $46,47]$ including chromatin remodeling [48-54]. Hippocampal LTM-specific cellular and molecular dynamics are clearly molded by time-of-day [55], supporting an intricate interplay between the circadian system and memory of yet unknown mechanism(s). Important components of the circadian timing mechanism and its plasticity are the members of the Period clock gene family (Per1 and Per2) [56-60], complemented by cAMP-dependent signaling [61]. Per1 being rhythmically expressed in the mouse hippocampus [42] and shown to modulate behavioral sensitization [62] implies a potential regulatory role for the clock gene protein PER1 in synaptic plasticity, particularly in the temporal modulation of learning and memory.

Both lesioning the master circadian clock in the suprachiasmatic nucleus (SCN) and silencing circadian outputs blunt LTM $[40,63]$. However, it is generally difficult to distinguish if these interventions affect LTM directly or indirectly by acting on endogenous hippocampal circadian oscillations via a local oscillator. Circadian core clock components are rhythmically expressed in the hippocampus of $\operatorname{Per}^{-1-}$ mice, yet their phases are shifted compared to control $\left(\right.$ Per $\left.^{+/+}\right)$mice, despite having a functional SCN clock that is properly phased to ambient lighting conditions [42]. 


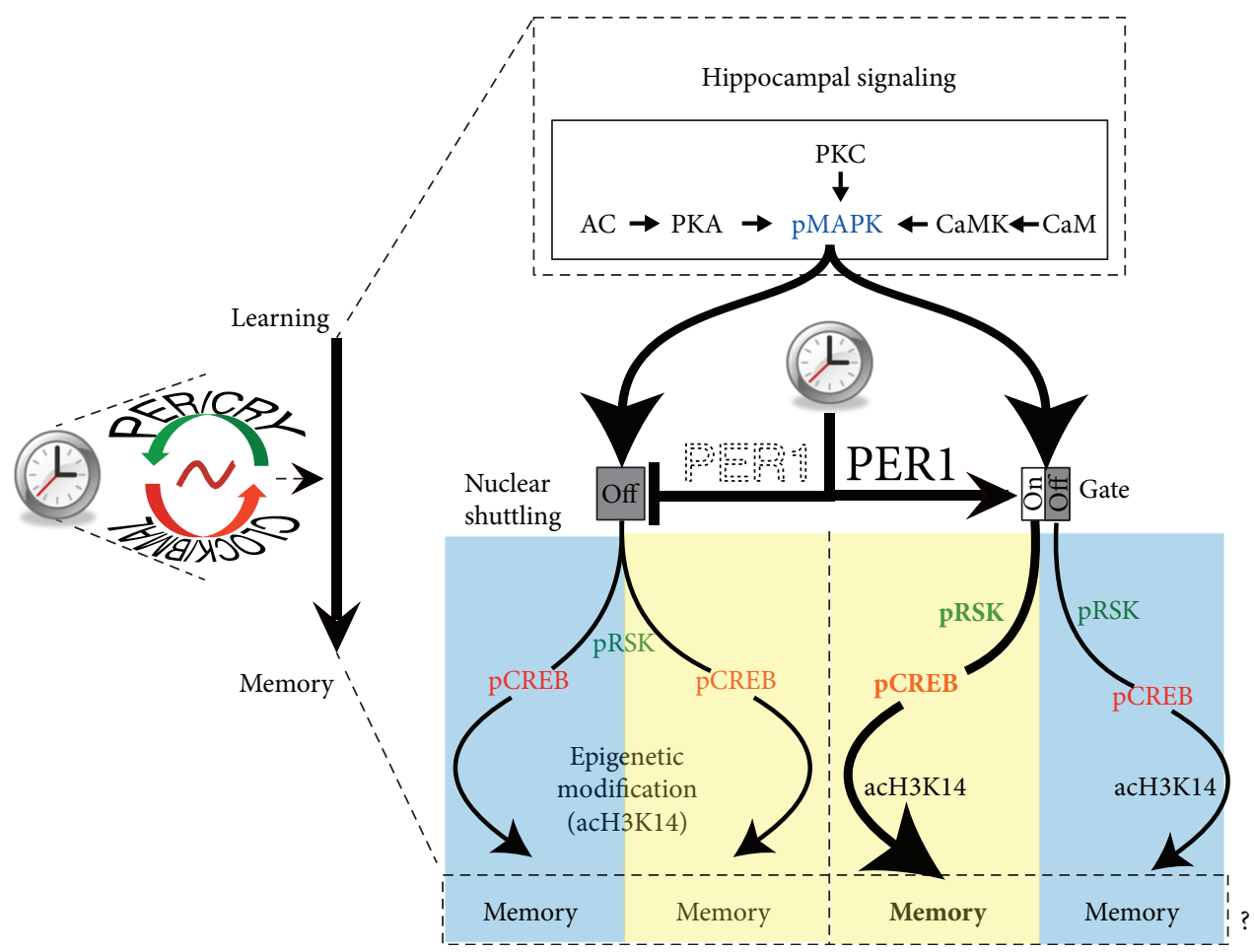

FIGURE 1: PER1, learning, and memory. Working model describing the role of the clock protein PER1 in gating daytime-dependent memory processing in the mouse hippocampus. As PER1 ties directly to memory-relevant molecular cascades, particularly pMAPK signaling, and is rhythmically expressed in the hippocampus, it can integrate circadian time into the molecular events necessary for memory processing (image modified from Rawashdeh et al. [65]).

The fact that $\operatorname{Per}^{-1-}$ mice are rhythmic under both diurnal and constant conditions similar to control littermates $\left(P e r 1^{+/+}\right)$suggests that these mice are ideal to investigate the role of PER1 in hippocampal physiology, particularly learning and memory processing as we have recently demonstrated (Figure 1) ([64-66].

There is compelling evidence that hippocampusdependent memory is mirrored by alterations in the plasticity of LTP $[45,47]$ and that LTP efficiency endows a circadian component [36]. The magnitude of LTP at perforant path-granule cell synapses in the dentate gyrus (DG) is compromised in Perl $^{-1-}$ mice, while basic properties of synaptic transmission and presynaptic short-term plasticity appear normal, indicating that functional deficits are not likely due to alterations in network excitability [65]. Late LTP at Schaffer collateral-CA1 synapses has been shown to underlie the maintenance of LTM in living animals $[44,45]$. These forms of synaptic plasticity require rapid translation of preexisting RNA in dendritic compartments $[67,68]$. Collectively, the recorded reduction in the amplitude of LTP observed in $\operatorname{Per}^{-1-}$ mice may therefore suggest a specific role for PER1 in the reinforcement/ consolidation of RNA synthesis-dependent LTP and associative spatial memories.

A comprehensive study demonstrated that the phosphorylation and hence the activation of both MAPK and CREB cycle rhythmically in the hippocampus [69]. Its functional significance is postulated to be important for the maintenance of long-term memories. It was later discovered that the phosphorylation of hippocampal CREB is PER1-dependent, since mice deficient for the Per1 gene are arrhythmic in hippocampal pCREB albeit $\mathrm{Per1}^{-1-}$ mice are rhythmic in their sleep/wake behavior under both diurnal and constant conditions, similar to $\mathrm{Perl}^{+/+}$mice. Furthermore, the in vitro induction of CREB phosphorylation via the cAMP/PKA/MAPK signaling pathway is also PER1-dependent.

Notably, long-term memory formation is dependent on different signaling cascades, many of which converge to activate the transcription factor CREB to initiate long-term memory-dependent gene expression [70-72]. The silencing of one or several of these pathways will likely alter learninginduced dynamics in CREB activation and consequently affect long-term memory formation. It has to be emphasized that while $\mathrm{Perl}^{-1-}$ mice show a reduction in the amplitude of in vivo LTP, they do acquire long-term spatial memory; however, compared to $\operatorname{Perl}^{+/+}$mice, day/night differences in memory performance are absent (ZT02 versus ZT14). This phenomenon may be linked to the absence of day/night variations in $\mathrm{PCREB}$ levels in $\mathrm{Per}^{-/-}$mice. Notably, this impairment in the temporal gating of PKA/MAPK-dependent phosphorylation of CREB in the absence of Perl is selective to the hippocampus, as PKA activation phosphorylates CREB in the pineal gland of $\operatorname{Perl}^{-1-}$ mice [65], a model system for cAMP signaling [73].

Whether the novel findings on the role of PER1 in modulating signaling to CREB phosphorylation by regulating the nuclear translocation of the CREB kinase 
pMAPK-activated ribosomal S6kinase (P90RSK) in vitro is the mechanism for the temporal gating in hippocampusdependent memory processing in vivo, is yet to be shown. This will not be an easy task as PER1 is a complex and highly regulated protein that could impose a regulatory function on hippocampal physiology via a plethora of regulatory signaling events as described next.

\section{The Complexity Surrounding PERIOD1 Function}

Period 1, originally named Rigui, is one of three homologous mammalian period genes which was first described by two independent labs in 1997 [74, 75]. The discovery of the other two orthologues (Period 2 and 3 ) and their interactions with core elements of the circadian oscillator creating autonomous interdependent transcriptional/translational feedback loops were published soon after [76, 77].

Within the transcriptional/translational feedback loop, the Per1 protein (PER1) acts as a negative regulator of the clocks' transcriptional activator complex, a heterodimer consisting of the core clock protein CLOCK [78] and BMAL1/MOP3 [79]. The CLOCK/BMAL1-complex binds to E-box elements which consist of a conserved sixbase-pair sequence. These E-boxes can be found in many promoter regions throughout the mammalian genome. The binding of the CLOCK/BMAL1-complex to an E-box facilitates downstream gene expression, like the period genes. Period proteins are known to cycle back to the nucleus where they bind to the CLOCK/BMAL1 complex, releasing the transcription activator complex from the E-box in the promoter region of the period genes and thus inhibiting Per1 expression. Comprehensive views on the workings of the TTFL and its complexities can be found in the following recent reviews $[80,81]$.

The fact that the Per1 promoter of both mouse and human $[82,83]$ consists of several E-boxes suggests a complex multimodal regulation of Per1 gene expression, involving the circadian regulation via CLOCK/BMAL1, and other gene-regulatory elements, particularly those involved in the acute (noncircadian, immediate, ligand-mediated) inductions. One example is the $\mathrm{CRE}^{*} \mathrm{C} / \mathrm{EBP}$ element which responds to increases in intracellular cAMP levels [84, 85], while others respond to interleukin 6 [85].

In an analysis of the forskolin-induced cAMP/PKA/ CREB/CRE-pathway in S49 lymphoma cells, Per1 (mRNA) was the only clock gene transcript significantly upregulated two hours poststimulation. Such acute upregulation is similar to known immediate early genes like the inducible cAMP early repressor (ICER) [86] and less of a characteristic for genes regulating the circadian clock.

In a more recent study, the CLOCK/BMAL1-driven PER1 upregulation and the associated signal transduction pathways in human liver cells were shown to be cAMPindependent [87]. To differentiate between CLOCK/BMAL1 action and ligand-based Per1 upregulation via second messenger-mediated pathways requires one or both pathways to be specifically inhibited using antisense techniques and/or pharmacological inhibitors [87]. It has to be noted that the dissection of and differentiation between the signaling events involved-CLOCK/BMAL1 E-box-mediated pathway versus acutely regulated second messengerdependent pathways that are dependent on CAMP/PKA or diacylglycerol (DAG)/calcium/calmodulin-dependent protein kinase (CamK)-are rather difficult in vivo. It is also important to mention that Per1 regulation can be cell- and tissue-specific, as shown in the mouse suprachiasmatic nucleus where CRE-dependent signaling appears to be essential for the circadian oscillation of clock genes $[61,88]$.

A recently discovered novel function for PER1 was described in primary hippocampal neurons in which PER1 signaling via the CAMP and MAPK pathways regulates the phosphorylation (activation) of its own transcription factor, CREB [65]. Here, the presence of PER1 determines the nucleocytoplasmic transport of the protein kinase pP90RSK, thereby gating downstream cAMP-dependent gene expression in the mouse hippocampus [89]. Notably, the original paper by Rawashdeh et al. utilized primary hippocampal cultures in order to study the function of PER1 in isolation of extrahippocampal influences on local hippocampal signaling [65]. This is important, because the $P e r 1^{-l-}$ mice used in this study were global knockouts.

Additional complexity in Per1 regulation emerges from the various posttranslational modifications that PER1 can undergo. Among the first established posttranslational modifications was its phosphorylation by casein kinase 1 [90], isoforms delta and epsilon, and maybe also gamma2. However, there are many potentially alternative threonine, serine, and tyrosine residues that can be phosphorylated by a variety of protein kinases as deduced from mass spectrometry, according to PhosphoSitePlus.

Depending on the specific phosphorylation pattern, PER1 homodimers can become targets for various protein phosphatases (confirmed is PP1), as well as ubiquitin transferases [91]. Each of these phosphorylation sites can potentially be of significant importance since the mutation of only a single PER1 phosphorylation site can have profound effects on, for example, circadian feeding behavior [92]. Some of the potentially phosphorylated amino acid residues determine the cytoplasmic localization of PER1, its resistance against proteasomal degradation, and nuclear translocation [93].

PER1 interacts either directly or indirectly with PER2 and 3 and CRY1 and 2, and its nuclear translocation permits its interaction with the CLOCK/BMAL1 complex [94] as well as some additional proteins like NONO, WDR5 [57], and SFPQ [95-97]. The most recent X-ray crystallographic analysis strongly suggests that besides the known PER1containing multiprotein complexes there are likely many others whose composition may be daytime and subcellular compartment-dependent [98].

In the near future, a combination of time-resolved immunoprecipitation or similar techniques $[98,99]$ in combination with mass spectrometric analysis of the different complexes, their components, and the posttranslational status of its protein components will shed new light on the complex yet delicate regulation of PER1 within a cell traveling through circadian time. 


\section{Thoughts to Consider}

What is driving hippocampal rhythmicity, particularly memory relevant signaling? One possibility is that the hippocampus houses a local circadian oscillator to gate hippocampal function. This idea however is not supported on the basis of data presented by Jilg et al., which show that all core elements of the circadian clock, with the exception of Per1/PER1, cycle in phase [42] and not as expected for the positive components of the TTFL to be in antiphase relative to the components of the negative limb. Hence, the hippocampus although rhythmic may not contain an autonomous "ticking" oscillator. Alternatively, rhythmic input of neuronal and/or humoral origin into the hippocampus could drive day/night differences in hippocampal function. For instance, melatonin, a pineal hormone whose synthesis and release are strictly confined to only the nighttime would in principle be able to set a nighttime-specific hippocampal tone $[100,101]$. Last but not least, what is the functional significance behind the diurnal and circadian rhythmicity in hippocampal signaling events? To date, much of the focus is on the genetic side of things with little emphasis on the more upstream rhythms in posttranslational modifications of kinases, their phosphatases, and phosphatase inhibitors. One could think of the diurnal and circadian variations in the activation state of signaling molecules as signatures defining different temporal states that determine the efficiency of memory processing at different times of the day and or the maintenance of long-term memories [40].

\section{Summary and Conclusion}

For an organism to register periodically, reoccurring stimuli (rewarding or harmful) require an efficient time management system to associate, retain, and recall temporal information. Molecular circadian clockworks, originally discovered in neurones of the SCN $[61,102]$, would be the ideal time management machinery. PER1, a core clockwork component, is also an important element in linking between circadian time cues (neuronal and/or hormonal) $[40,100]$ and memory processing, with cAMP signaling [61] and epigenetic modifications [103] at its center. In fact, clock genes, constituting integral parts of the cellular and biochemical machinery that store information about time, may also be a molecular prerequisite for memory storage in a much broader sense than previously anticipated. This may be relevant for adaptive brain functions in both health and disease [53, 54]. As long-term memory is afflicted in both $P e r 1^{-1-}$ mice and Per-mutant flies [38, 66], the memory-associated function of this clock gene appears to be preserved over some 700 million years of evolutionary distance.

\section{Conflicts of Interest}

The authors declare no competing interests.

\section{References}

[1] Y. Dudai, The Neurobiology of Memory: Concepts, Findings, Trends, Oxford University Press. xi, Oxford England; New York, 1989.

[2] F. Crick, The Astonishing Hypothesis: The Scientific Search for the Soul, Maxwell Macmillan International, New York: Scribner, 1994.

[3] Y. Dudai, "Why should 'Learning' and 'Memory' be redefined (or an agenda for focused reductionism)," Concepts in Neuroscience, vol. 3, no. 1, pp. 99-121, 1992.

[4] Y. Dudai, Memory From a to Z, Oxford University Press, Oxford, 2002.

[5] L. R. Squire, "Memory and brain systems: 1969-2009," Journal of Neuroscience, vol. 29, no. 41, pp. 12711-12716, 2009.

[6] K. Foerde, B. J. Knowlton, and R. A. Poldrack, "Modulation of competing memory systems by distraction," Proceedings of the National Academy of Sciences of the United States of America, vol. 103, no. 31, pp. 11778-11783, 2006.

[7] B. J. Knowlton, J. A. Mangels, and L. R. Squire, "A neostriatal habit learning system in humans," Science, vol. 273, no. 5280, pp. 1399-1402, 1996.

[8] M. G. Packard, R. Hirsh, and N. M. White, "Differential effects of fornix and caudate nucleus lesions on two radial maze tasks: evidence for multiple memory systems," Journal of Neuroscience, vol. 9, no. 5, pp. 1465-1472, 1989.

[9] H. Eichenbaum, A. Fagan, P. Mathews, and N. J. Cohen, "Hippocampal system dysfunction and odor discrimination learning in rats: impairment of facilitation depending on representational demands," Behavioral Neuroscience, vol. 102, no. 3, pp. 331-339, 1988.

[10] T. W. Berger and W. B. Orr, "Hippocampectomy selectively disrupts discrimination reversal conditioning of the rabbit nictitating membrane response," Behavioural Brain Research, vol. 8 , no. 1 , pp. $49-68,1983$.

[11] A. A. Buerger, C. G. Gross, and C. E. Rocha-Miranda, "Effects of ventral putamen lesions on discrimination learning by monkeys," Journal of Comparative and Physiological Psychology, vol. 86, no. 3, pp. 440-446, 1974.

[12] S. Zola-Morgan, L. R. Squire, and M. Mishkin, "The neuroanatomy of amnesia: amygdala-hippocampus versus temporal stem," Science, vol. 218, no. 4579, pp. 1337-1339, 1982.

[13] D. Gaffan, "Recognition impaired and association intact in the memory of monkeys after transection of the fornix," Journal of Comparative and Physiological Psychology, vol. 86, no. 6, pp. 1100-1109, 1974.

[14] B. L. Malamut, R. C. Saunders, and M. Mishkin, "Monkeys with combined amygdalo-hippocampal lesions succeed in object discrimination learning despite 24-hour intertrial intervals," Behavioral Neuroscience, vol. 98, no. 5, pp. 759$769,1984$.

[15] C. P. Duncan, "The retroactive effect of electroshock on learning," Journal of Comparative and Physiological Psychology, vol. 42, no. 1, pp. 32-44, 1949.

[16] H. Ebbinghaus, "Memory: a contribution to experimental psychology," Annals of Neurosciences, vol. 20, no. 4, pp. 155-156, 2013.

[17] L. J. Kamin, "The retention of an incompletely learned avoidance response," Journal of Comparative and Physiological Psychology, vol. 50, no. 5, pp. 457-460, 1957. 
[18] B. Gerber and R. Menzel, "Contextual modulation of memory consolidation," Learning \& Memory, vol. 7, no. 3, pp. 151$158,2000$.

[19] F. A. Holloway and R. Wansley, "Multiphasic retention deficits at periodic intervals after passive-avoidance learning," Science, vol. 180, no. 4082, pp. 208-210, 1973.

[20] R. A. Wansley and F. A. Holloway, "Oscillations in retention performance after passive avoidance training," Learning and Motivation, vol. 7, no. 2, pp. 296-302, 1976.

[21] F. K. Stephan and N. S. Kovacevic, "Multiple retention deficit in passive avoidance in rats is eliminated by suprachiasmatic lesions," Behavioral Biology, vol. 22, no. 4, pp. 456-462, 1978.

[22] R. A. Wansley and F. A. Holloway, "Multiple retention deficits following one-trial appetitive training," Behavioral Biology, vol. 14, no. 2, pp. 135-149, 1975.

[23] F. A. Holloway, "State-dependent retrieval based on natural states," in Symposium paper presented at the meeting of the Southwestern Psychological Association, Houston, 1975.

[24] C. A. Barnes, B. L. McNaughton, G. V. Goddard, R. M. Douglas, and R. Adamec, "Circadian rhythm of synaptic excitability in rat and monkey central nervous system," Science, vol. 197, no. 4298, pp. 91-92, 1977.

[25] L. E. Scheving, W. H. Harrison, P. Gordon, and J. E. Pauly, "Daily fluctuation (circadian and ultradian) in biogenic amines of the rat brain," American Journal of PhysiologyLegacy Content, vol. 214, no. 1, pp. 166-173, 1968.

[26] W. N. Tapp and F. A. Holloway, "Phase shifting circadian rhythms produces retrograde amnesia," Science, vol. 211, no. 4486, pp. 1056-1058, 1981.

[27] M. Fekete, J. M. van Ree, R. J. M. Niesink, and D. de Wied, "Disrupting circadian rhythms in rats induces retrograde amnesia," Physiology \& Behavior, vol. 34, no. 6, pp. 883887, 1985.

[28] M. Fekete, J. M. Van Ree, and D. De Wied, "The ACTH-(4-9) analog ORG 2766 and desglycinamide ${ }^{9}-\left(\mathrm{Arg}^{8}\right)$-vasopressin reverse the retrograde amnesia induced by disrupting circadian rhythms in rats," Peptides, vol. 7, no. 4, pp. 563-568, 1986.

[29] D. De Wied, "Hormonal influences on motivation, learning, and memory processes," Hospital Practice, vol. 11, no. 1, pp. 123-131, 1976.

[30] E. A. Antoniadis, C. H. Ko, M. R. Ralph, and R. J. McDonald, "Circadian rhythms, aging and memory," Behavioural Brain Research, vol. 114, no. 1-2, pp. 221-233, 2000.

[31] B. D. Devan, E. H. Goad, H. L. Petri et al., "Circadian phase-shifted rats show normal acquisition but impaired long-term retention of place information in the water task," Neurobiology of Learning and Memory, vol. 75, no. 1, pp. 51-62, 2001.

[32] D. Chaudhury and C. S. Colwell, "Circadian modulation of learning and memory in fear-conditioned mice," Behavioural Brain Research, vol. 133, no. 1, pp. 95-108, 2002.

[33] V. S. Valentinuzzi, D. E. Kolker, M. H. Vitaterna, E. A. M. Ferrari, J. S. Takahashi, and F. W. Turek, "Effect of circadian phase on context and cued fear conditioning in C57BL/6J mice," Animal Learning \& Behavior, vol. 29, no. 2, pp. 133142, 2001.

[34] V. S. Valentinuzzi, L. Menna-Barreto, and G. F. Xavier, "Effect of circadian phase on performance of rats in the Morris water maze task," Journal of Biological Rhythms, vol. 19, no. 4, pp. 312-324, 2004.
[35] R. I. Fernandez, L. C. Lyons, J. Levenson, O. Khabour, and A. Eskin, "Circadian modulation of long-term sensitization in Aplysia," Proceedings of the National Academy of Sciences of the United States of America, vol. 100, no. 24, pp. 1441514420, 2003.

[36] D. Chaudhury, L. M. Wang, and C. S. Colwell, "Circadian regulation of hippocampal long-term potentiation," Journal of Biological Rhythms, vol. 20, no. 3, pp. 225-236, 2005.

[37] L. C. Lyons and G. Roman, "Circadian modulation of shortterm memory in Drosophila," Learning \& Memory, vol. 16, no. 1, pp. 19-27, 2009

[38] T. Sakai, T. Tamura, T. Kitamoto, and Y. Kidokoro, "A clock gene, period, plays a key role in long-term memory formation in Drosophila," Proceedings of the National Academy of Sciences of the United States of America, vol. 101, no. 45, pp. 16058-16063, 2004.

[39] C. H. Ko, R. J. McDonald, and M. R. Ralph, "The suprachiasmatic nucleus is not required for temporal gating of performance on a reward-based learning and memory task," Biological Rhythm Research, vol. 34, no. 2, pp. 177-192, 2003.

[40] T. H. Phan, G. C.- K. Chan, C. B. Sindreu, K. L. Eckel-Mahan, and D. R. Storm, "The diurnal oscillation of MAP (mitogenactivated protein) kinase and adenylyl cyclase activities in the hippocampus depends on the suprachiasmatic nucleus," Journal of Neuroscience, vol. 31, no. 29, pp. 10640-10647, 2011.

[41] L. M.-C. Wang, J. M. Dragich, T. Kudo et al., "Expression of the circadian clock gene Period2 in the hippocampus: possible implications for synaptic plasticity and learned behaviour," ASN Neuro, vol. 1, no. 3, article AN20090020, 2009.

[42] A. Jilg, S. Lesny, N. Peruzki et al., "Temporal dynamics of mouse hippocampal clock gene expression support memory processing," Hippocampus, vol. 20, no. 3, pp. 377388,2010

[43] A. Barco, J. M. Alarcon, and E. R. Kandel, "Expression of constitutively active CREB protein facilitates the late phase of long-term potentiation by enhancing synaptic capture," Cell, vol. 108, no. 5, pp. 689-703, 2002.

[44] E. Pastalkova, P. Serrano, D. Pinkhasova, E. Wallace, A. A. Fenton, and T. C. Sacktor, "Storage of spatial information by the maintenance mechanism of LTP," Science, vol. 313, no. 5790, pp. 1141-1144, 2006.

[45] J. R. Whitlock, A. J. Heynen, M. G. Shuler, and M. F. Bear, "Learning induces long-term potentiation in the hippocampus," Science, vol. 313, no. 5790, pp. 1093-1097, 2006.

[46] U. Frey, Y. Y. Huang, and E. R. Kandel, "Effects of cAMP simulate a late stage of LTP in hippocampal CA1 neurons," Science, vol. 260, no. 5114, pp. 1661-1664, 1993.

[47] T. Abel, P. V. Nguyen, M. Barad, T. A. S. Deuel, E. R. Kandel, and R. Bourtchouladze, "Genetic demonstration of a role for PKA in the late phase of LTP and in hippocampus-based long-term memory," Cell, vol. 88, no. 5, pp. 615-626, 1997.

[48] T. L. Roth and J. D. Sweatt, "Regulation of chromatin structure in memory formation," Current Opinion in Neurobiology, vol. 19, no. 3, pp. 336-342, 2009.

[49] J. M. Levenson, K. J. O'Riordan, K. D. Brown, M. A. Trinh, D. L. Molfese, and J. D. Sweatt, "Regulation of histone acetylation during memory formation in the hippocampus," Journal of Biological Chemistry, vol. 279, no. 39, pp. 4054540559, 2004. 
[50] S. Gupta, S. Y. Kim, S. Artis et al., "Histone methylation regulates memory formation," Journal of Neuroscience, vol. 30, no. 10, pp. 3589-3599, 2010.

[51] F. Tian, X. Z. Hu, X. Wu et al., "Dynamic chromatin remodeling events in hippocampal neurons are associated with NMDA receptor-mediated activation of $B d n f$ gene promoter 1," Journal of Neurochemistry, vol. 109, no. 5, pp. 1375-1388, 2009.

[52] N. Buttner, S. A. Johnsen, S. Kugler, and T. Vogel, "Af9/Mllt3 interferes with Tbr1 expression through epigenetic modification of histone H3K79 during development of the cerebral cortex," Proceedings of the National Academy of Sciences of the United States of America, vol. 107, no. 15, pp. 70427047, 2010.

[53] R. G. Hunter, K. J. McCarthy, T. A. Milne, D. W. Pfaff, and B. S. McEwen, "Regulation of hippocampal H3 histone methylation by acute and chronic stress," Proceedings of the National Academy of Sciences of the United States of America, vol. 106, no. 49, pp. 20912-20917, 2009.

[54] S. Peleg, F. Sananbenesi, A. Zovoilis et al., "Altered histone acetylation is associated with age-dependent memory impairment in mice," Science, vol. 328, no. 5979, pp. 753-756, 2010.

[55] J. R. Gerstner, L. C. Lyons, K. P. Wright et al., "Cycling behavior and memory formation," Journal of Neuroscience, vol. 29, no. 41, pp. 12824-12830, 2009.

[56] U. Albrecht, Z. S. Sun, G. Eichele, and C. C. Lee, “A differential response of two putative mammalian circadian regulators, mper 1 and mper2, to light," Cell, vol. 91, no. 7, pp. 1055-1064, 1997.

[57] S. A. Brown, J. Ripperger, S. Kadener et al., "PERIOD1-associated proteins modulate the negative limb of the mammalian circadian oscillator," Science, vol. 308, no. 5722, pp. 693-696, 2005.

[58] Y. Shigeyoshi, K. Taguchi, S. Yamamoto et al., "Light-induced resetting of a mammalian circadian clock is associated with rapid induction of the mPer 1 transcript," Cell, vol. 91, no. 7, pp. 1043-1053, 1997.

[59] Z. Travnickova-Bendova, N. Cermakian, S. M. Reppert, and P. Sassone-Corsi, "Bimodal regulation of mPeriod promoters by CREB-dependent signaling and CLOCK/BMAL1 activity," Proceedings of the National Academy of Sciences of the United States of America, vol. 99, no. 11, pp. 7728-7733, 2002.

[60] C. von Gall, M. L. Garabette, C. A. Kell et al., "Rhythmic gene expression in pituitary depends on heterologous sensitization by the neurohormone melatonin," Nature Neuroscience, vol. 5, no. 3, pp. 234-238, 2002.

[61] J. S. O'Neill, E. S. Maywood, J. E. Chesham, J. S. Takahashi, and M. H. Hastings, "cAMP-dependent signaling as a core component of the mammalian circadian pacemaker," Science, vol. 320, no. 5878, pp. 949-953, 2008.

[62] C. Abarca, U. Albrecht, and R. Spanagel, "Cocaine sensitization and reward are under the influence of circadian genes and rhythm," Proceedings of the National Academy of Sciences of the United States of America, vol. 99, no. 13, pp. 9026-9030, 2002.

[63] N. F. Ruby, C. E. Hwang, C. Wessells et al., "Hippocampal-dependent learning requires a functional circadian system," Proceedings of the National Academy of Sciences of the United States of America, vol. 105, no. 40, pp. 1559315598, 2008 .
[64] O. Rawashdeh, A. Jilg, P. Jedlicka et al., "PERIOD1 coordinates hippocampal rhythms and memory processing with daytime," Hippocampus, vol. 24, no. 6, pp. 712-723, 2014.

[65] O. Rawashdeh, A. Jilg, E. Maronde, J. Fahrenkrug, and J. H. Stehle, "Period1 gates the circadian modulation of memoryrelevant signaling in mouse hippocampus by regulating the nuclear shuttling of the CREB kinase pP90RSK," Journal of Neurochemistry, vol. 138, no. 5, pp. 731-745, 2016.

[66] P. Bechstein, N. J. Rehbach, G. Yuhasingham et al., “The clock gene Period1 regulates innate routine behaviour in mice," Proceedings of the Royal Society B: Biological Sciences, vol. 281, no. 1781, article 20140034, 2014.

[67] A. Govindarajan, R. J. Kelleher, and S. Tonegawa, "A clustered plasticity model of long-term memory engrams," Nature Reviews Neuroscience, vol. 7, no. 7, pp. 575-583, 2006.

[68] K. M. Huber, M. S. Kayser, and M. F. Bear, "Role for rapid dendritic protein synthesis in hippocampal mGluR-dependent long-term depression," Science, vol. 288, no. 5469, pp. 1254 1256, 2000.

[69] K. L. Eckel-Mahan, T. Phan, S. Han et al., "Circadian oscillation of hippocampal MAPK activity and cAmp: implications for memory persistence," Nature Neuroscience, vol. 11, no. 9, pp. 1074-1082, 2008.

[70] R. Bourtchouladze, T. Abel, N. Berman, R. Gordon, K. Lapidus, and E. R. Kandel, "Different training procedures recruit either one or two critical periods for contextual memory consolidation, each of which requires protein synthesis and PKA," Learning \& Memory, vol. 5, no. 4-5, pp. 365374, 1998.

[71] R. P. Matthews, C. R. Guthrie, L. M. Wailes, X. Zhao, A. R. Means, and G. S. McKnight, "Calcium/calmodulin-dependent protein kinase types II and IV differentially regulate CREB-dependent gene expression," Molecular and Cellular Biology, vol. 14, no. 9, pp. 6107-6116, 1994.

[72] F. Wei, C. S. Qiu, J. Liauw et al., "Calcium-calmodulindependent protein kinase IV is required for fear memory," Nature Neuroscience, vol. 5, no. 6, pp. 573-579, 2002.

[73] J. H. Stehle, N. S. Foulkes, C. A. Molina, V. Simonneaux, P. Pévet, and P. Sassone-Corsi, "Adrenergic signals direct rhythmic expression of transcriptional represser CREM in the pineal gland," Nature, vol. 365, no. 6444, pp. 314-320, 1993.

[74] Z. S. Sun, U. Albrecht, O. Zhuchenko, J. Bailey, G. Eichele, and C. C. Lee, "RIGUI, a putative mammalian ortholog of the Drosophila period gene," Cell, vol. 90, no. 6, pp. 1003 1011, 1997.

[75] H. Tei, H. Okamura, Y. Shigeyoshi et al., "Circadian oscillation of a mammalian homologue of the Drosophila period gene," Nature, vol. 389, no. 6650, pp. 512-516, 1997.

[76] L. P. Shearman, M. J. Zylka, D. R. Weaver, L. F. Kolakowski Jr, and S. M. Reppert, "Two period homologs: circadian expression and photic regulation in the suprachiasmatic nuclei," Neuron, vol. 19, no. 6, pp. 1261-1269, 1997.

[77] M. J. Zylka, L. P. Shearman, D. R. Weaver, and S. M. Reppert, "Three period homologs in mammals: differential light responses in the suprachiasmatic circadian clock and oscillating transcripts outside of brain," Neuron, vol. 20, no. 6, pp. 1103-1110, 1998.

[78] M. Vitaterna, D. King, A. Chang et al., "Mutagenesis and mapping of a mouse gene, clock, essential for circadian behavior," Science, vol. 264, no. 5159, pp. 719-725, 1994. 
[79] N. Gekakis, D. Staknis, H. B. Nguyen et al., "Role of the CLOCK protein in the mammalian circadian mechanism," Science, vol. 280, no. 5369, pp. 1564-1569, 1998.

[80] U. Albrecht, "Timing to perfection: the biology of central and peripheral circadian clocks," Neuron, vol. 74, no. 2, pp. 246260, 2012.

[81] J. A. Mohawk, C. B. Green, and J. S. Takahashi, "Central and peripheral circadian clocks in mammals," Annual Review of Neuroscience, vol. 35, no. 1, pp. 445-462, 2012.

[82] A. Hida, N. Koike, M. Hirose, M. Hattori, Y. Sakaki, and H. Tei, "The human and mouse Period1 genes: five wellconserved E-boxes additively contribute to the enhancement of mPer1 transcription," Genomics, vol. 65, no. 3, pp. 224233, 2000.

[83] D. Motzkus, E. Maronde, U. Grunenberg, C. C. Lee, W. G. Forssmann, and U. Albrecht, "The human PER1 gene is transcriptionally regulated by multiple signaling pathways," FEBS Letters, vol. 486, no. 3, pp. 315-319, 2000.

[84] E. Maronde and D. Motzkus, "Oscillation of human period 1 (hPER1) reporter gene activity in human neuroblastoma cells in vivo," Chronobiology International, vol. 20, no. 4, pp. 671681, 2003.

[85] D. Motzkus, U. Albrecht, and E. Maronde, "The human PER1 gene is inducible by interleukin-6," Journal of Molecular Neuroscience, vol. 18, no. 1-2, pp. 105-110, 2002.

[86] A. C. Zambon, L. Zhang, S. Minovitsky et al., "Gene expression patterns define key transcriptional events in cell-cycle regulation by cAMP and protein kinase A," Proceedings of the National Academy of Sciences of the United States of America, vol. 102, no. 24, pp. 8561-8566, 2005.

[87] D. Motzkus, S. Loumi, C. Cadenas, C. Vinson, W.-. G. Forssmann, and E. Maronde, "Activation of human period-1 by PKA or CLOCK/BMAL1 is conferred by separate signal transduction pathways," Chronobiology International, vol. 24, no. 5, pp. 783-792, 2007.

[88] M. H. Hastings, E. S. Maywood, and J. S. O'Neill, "Cellular circadian pacemaking and the role of cytosolic rhythms," Current Biology, vol. 18, no. 17, pp. R805-R815, 2008.

[89] S. H. Yoo and K. Eckel-Mahan, "Hippocampal PER1: a circadian sentinel controlling RSKy activity during memory formation," Journal of Neurochemistry, vol. 138, no. 5, pp. 650-652, 2016.

[90] C. Lee, J. P. Etchegaray, F. R. A. Cagampang, A. S. I. Loudon, and S. M. Reppert, "Posttranslational mechanisms regulate the mammalian circadian clock," Cell, vol. 107, no. 7, pp. 855-867, 2001.

[91] E. E. Zhang, A. C. Liu, T. Hirota et al., "A genome-wide RNAi screen for modifiers of the circadian clock in human cells," Cell, vol. 139, no. 1, pp. 199-210, 2009.

[92] Z. Liu, M. Huang, X. Wu et al., "PER1 phosphorylation specifies feeding rhythm in mice," Cell Reports, vol. 7, no. 5, pp. 1509-1520, 2014.

[93] K. Vanselow, J. T. Vanselow, P. O. Westermark et al., "Differential effects of PER2 phosphorylation: molecular basis for the human familial advanced sleep phase syndrome (FASPS)," Genes \& Development, vol. 20, no. 19, pp. 26602672,2006

[94] C. Lee, D. R. Weaver, and S. M. Reppert, "Direct association between mouse PERIOD and CKI $\varepsilon$ is critical for a functioning circadian clock," Molecular and Cellular Biology, vol. 24, no. 2, pp. 584-594, 2004.
[95] H. A. Duong, M. S. Robles, D. Knutti, and C. J. Weitz, "A molecular mechanism for circadian clock negative feedback," Science, vol. 332, no. 6036, pp. 1436-1439, 2011.

[96] H. A. Duong and C. J. Weitz, "Temporal orchestration of repressive chromatin modifiers by circadian clock period complexes," Nature Structural \& Molecular Biology, vol. 21, no. 2, pp. 126-132, 2014.

[97] J. Y. Kim, P. B. Kwak, M. Gebert, H. A. Duong, and C. J. Weitz, "Purification and analysis of PERIOD protein complexes of the mammalian circadian clock," Methods in Enzymology, vol. 551, pp. 197-210, 2015.

[98] R. P. Aryal, P. B. Kwak, A. G. Tamayo et al., "Macromolecular assemblies of the mammalian circadian clock," Molecular Cell, vol. 67, no. 5, pp. 770-782.e6, 2017.

[99] H. Heide, L. Bleier, M. Steger et al., "Complexome profiling identifies TMEM126B as a component of the mitochondrial complex I assembly complex," Cell Metabolism, vol. 16, no. 4, pp. 538-549, 2012.

[100] O. Rawashdeh, N. H. de Borsetti, G. Roman, and G. M. Cahill, "Melatonin suppresses nighttime memory formation in zebrafish," Science, vol. 318, no. 5853, pp. 1144-1146, 2007.

[101] L. M. Wang, N. A. Suthana, D. Chaudhury, D. R. Weaver, and C. S. Colwell, "Melatonin inhibits hippocampal long-term potentiation," European Journal of Neuroscience, vol. 22, no. 9, pp. 2231-2237, 2005.

[102] S. M. Reppert and D. R. Weaver, "Coordination of circadian timing in mammals," Nature, vol. 418, no. 6901, pp. 935941, 2002.

[103] C. G. Vecsey, J. D. Hawk, K. M. Lattal et al., "Histone deacetylase inhibitors enhance memory and synaptic plasticity via CREB: CBP-dependent transcriptional activation," Journal of Neuroscience, vol. 27, no. 23, pp. 6128-6140, 2007.

[104] M. R. M. Vianna, L. A. Izquierdo, D. M. Barros et al., "Differential role of hippocampal cAMP-dependent protein kinase in short- and long-term memory," Neurochemical Research, vol. 25, no. 5, pp. 621-626, 2000.

[105] Y. F. Li, Y. F. Cheng, Y. Huang et al., "Phosphodiesterase-4D knock-out and RNA interference-mediated knock-down enhance memory and increase hippocampal neurogenesis via increased cAMP signaling," Journal of Neuroscience, vol. 31, no. 1, pp. 172-183, 2011.

[106] A. J. Park, R. Havekes, J. H. K. Choi et al., "A presynaptic role for PKA in synaptic tagging and memory," Neurobiology of Learning and Memory, vol. 114, pp. 101-112, 2014.

[107] M. T. Grimes, C. W. Harley, A. Darby-King, and J. H. McLean, "PKA increases in the olfactory bulb act as unconditioned stimuli and provide evidence for parallel memory systems: pairing odor with increased PKA creates intermediate- and long-term, but not short-term, memories," Learning \& Memory, vol. 19, no. 3, pp. 107-115, 2012.

[108] R. Havekes, D. A. Canton, A. J. Park et al., "Gravin orchestrates protein kinase a and $\beta 2$-adrenergic receptor signaling critical for synaptic plasticity and memory," Journal of Neuroscience, vol. 32, no. 50, pp. 18137-18149, 2012.

[109] M. R. M. Vianna, D. M. Barros, T. Silva et al., "Pharmacological demonstration of the differential involvement of protein kinase $\mathrm{C}$ isoforms in short- and long-term memory formation and retrieval of one-trial avoidance in rats," Psychopharmacology, vol. 150, no. 1, pp. 77-84, 2000.

[110] R. Bernabeu, I. Izquierdo, M. Cammarota, D. Jerusalinsky, and J. H. Medina, "Learning-specific, time-dependent 
increase in $\left[{ }^{3} \mathrm{H}\right]$ phorbol dibutyrate binding to protein kinase $\mathrm{C}$ in selected regions of the rat brain," Brain Research, vol. 685, no. 1-2, pp. 163-168, 1995.

[111] M. Cammarota, G. Paratcha, M. L. de Stein, R. Bernabeu, I. Izquierdo, and J. H. Medina, "B-50/GAP-43 phosphorylation and $\mathrm{PKC}$ activity are increased in rat hippocampal synaptosomal membranes after an inhibitory avoidance training," Neurochemical Research, vol. 22, no. 4, pp. 499505, 1997.

[112] L. Li, L. You, B. Sunyer et al., "Hippocampal protein kinase C family members in spatial memory retrieval in the mouse," Behavioural Brain Research, vol. 258, pp. 202-207, 2014.

[113] J. Athos, S. Impey, V. V. Pineda, X. Chen, and D. R. Storm, "Hippocampal CRE-mediated gene expression is required for contextual memory formation," Nature Neuroscience, vol. 5, no. 11, pp. 1119-1120, 2002.

[114] C. Zamorano, J. Fernández-Albert, D. R. Storm, X. Carné, and C. Sindreu, "Memory retrieval re-activates Erk1/2 signaling in the same set of CA1 neurons recruited during conditioning," Neuroscience, vol. 370, pp. 101-111, 2018.

[115] X. Chen, M. G. Garelick, H. Wang, V. Li, J. Athos, and D. R. Storm, "PI3 kinase signaling is required for retrieval and extinction of contextual memory," Nature Neuroscience, vol. 8, no. 7, pp. 925-931, 2005.

[116] C.-K. Chiang, B. Xu, N. Mehta et al., "Phosphoproteome profiling reveals circadian clock regulation of posttranslational modifications in the murine hippocampus," Frontiers in Neurology, vol. 8, p. 110, 2017.

[117] R. Lamprecht, S. Hazvi, and Y. Dudai, "cAMP response element-binding protein in the amygdala is required for long- but not short-term conditioned taste aversion memory," The Journal of Neuroscience, vol. 17, no. 21, pp. 84438450, 1997.

[118] J. J. Brightwell, C. A. Smith, R. A. Countryman, R. L. Neve, and P. J. Colombo, "Hippocampal overexpression of mutant CREB blocks long-term, but not short-term memory for a socially transmitted food preference," Learning \& Memory, vol. 12, no. 1, pp. 12-17, 2005.

[119] S. Kida, S. A. Josselyn, S. P. de Ortiz et al., "CREB required for the stability of new and reactivated fear memories," Nature Neuroscience, vol. 5, no. 4, pp. 348-355, 2002.

[120] S. T. Wong, J. Athos, X. A. Figueroa et al., "Calcium-stimulated adenylyl cyclase activity is critical for hippocampusdependent long-term memory and late phase LTP," Neuron, vol. 23, no. 4, pp. 787-798, 1999.

[121] K. Takao, K. Tanda, K. Nakamura et al., "Comprehensive behavioral analysis of calcium/calmodulin-dependent protein kinase IV knockout mice," PLoS One, vol. 5, no. 3, article e9460, 2010.

[122] H. Kang, L. D. Sun, C. M. Atkins, T. R. Soderling, M. A. Wilson, and S. Tonegawa, "An important role of neural activity-dependent CaMKIV signaling in the consolidation of long-term memory," Cell, vol. 106, no. 6, pp. 771-783, 2001.

[123] C. Cirelli, C. M. Gutierrez, and G. Tononi, "Extensive and divergent effects of sleep and wakefulness on brain gene expression," Neuron, vol. 41, no. 1, pp. 35-43, 2004.

[124] S. Miller, M. Yasuda, J. K. Coats, Y. Jones, M. E. Martone, and M. Mayford, "Disruption of dendritic translation of CaMKII $\alpha$ impairs stabilization of synaptic plasticity and memory consolidation," Neuron, vol. 36, no. 3, pp. 507-519, 2002.
[125] G. Szapiro, L. A. Izquierdo, M. Alonso et al., "Participation of hippocampal metabotropic glutamate receptors, protein kinase $\mathrm{A}$ and mitogen-activated protein kinases in memory retrieval," Neuroscience, vol. 99, no. 1, pp. 1-5, 2000.

[126] N. Kon, T. Yoshikawa, S. Honma et al., "CaMKII is essential for the cellular clock and coupling between morning and evening behavioral rhythms," Genes \& Development, vol. 28, no. 10, pp. 1101-1110, 2014. 


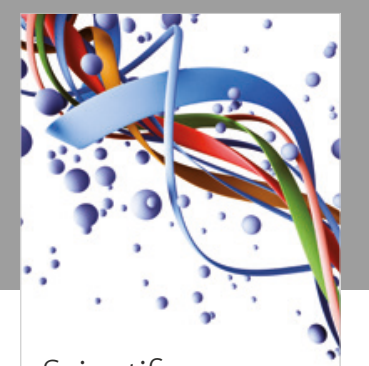

Scientifica
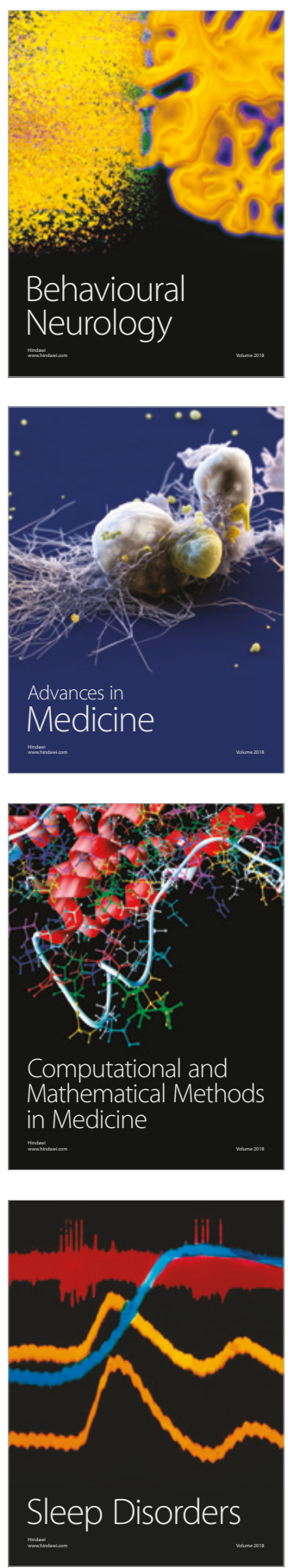

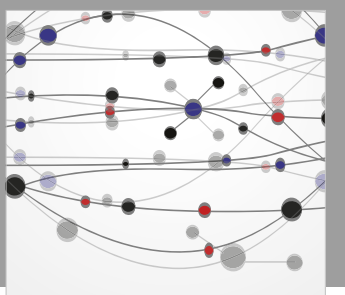

The Scientific World Journal

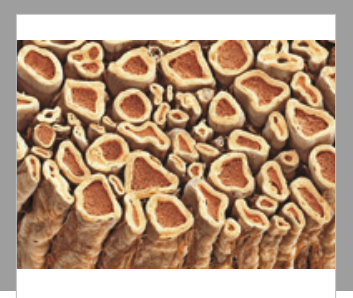

Case Reports in

Neurological Medicine

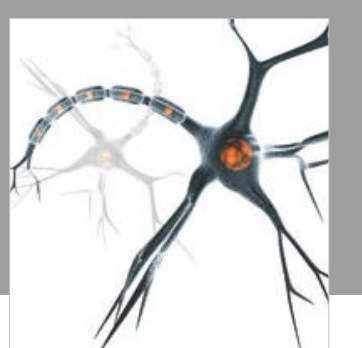

Neural Plasticity

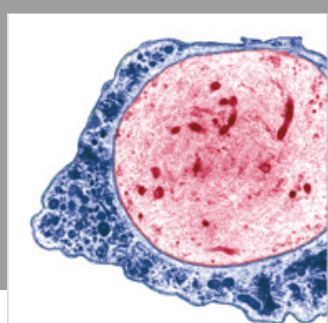

Multiple Sclerosis

International

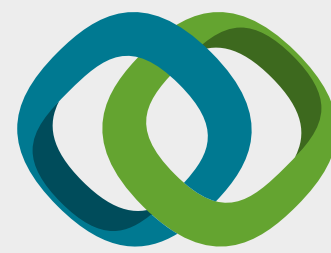

Hindawi

Submit your manuscripts at

www.hindawi.com
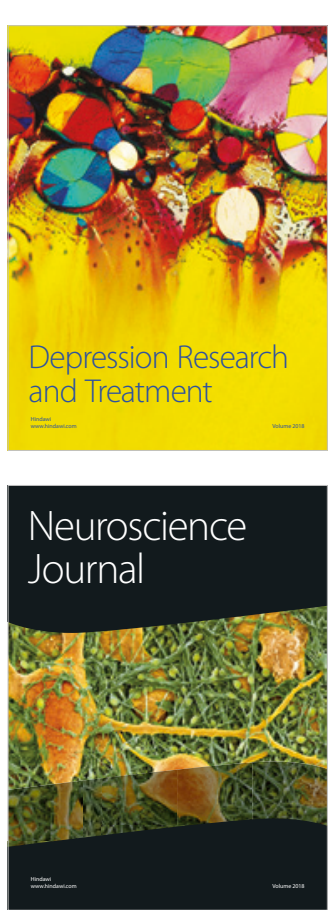

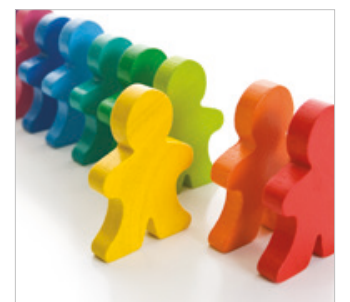

Autism

Research and Treatment
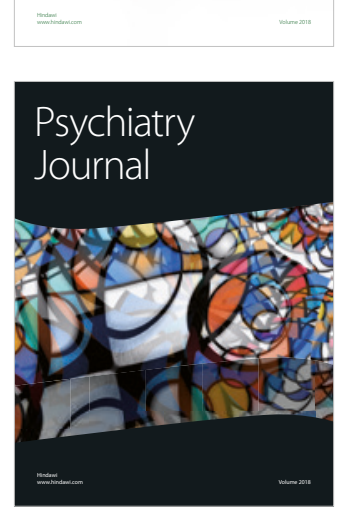
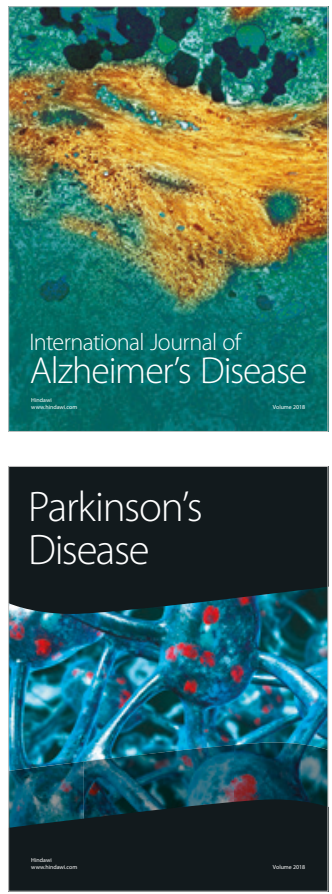
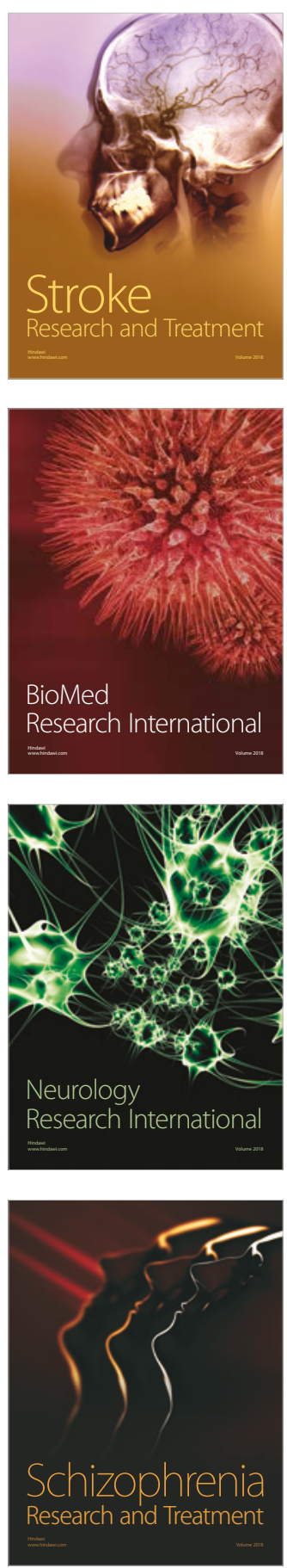